\title{
Development of Large-Scale Land Information System (LIS) by Using Geographic Information System (GIS) and Field Surveying
}

\author{
Asma Th. Ibraheem \\ Department of Civil Engineering, College of Engineering, Nahrain University, Baghdad, Iraq \\ Email: drasmathamir@yahoo.com
}

Received October 14, 2011; revised January 12, 2012, accepted January 20, 2012

\begin{abstract}
Cadastral maps are an important component of land administration in most countries. In virtually all developed countries, the needs of computerized land and geographic information systems (LIS/GIS) has given urgent impetus to computerizing cadastral maps and creating digital cadastral data bases (DCDB). This process is creating many institutional, legal, technical and administrative problems. This desire to establish DCDBs is being given increased impetus due to a new range of enabling technologies such as satellite position fixing (GPS), improved spatial data collection techniques such as digital theodolites and "soft copy" photogrammetry, as well as a vast range of new information and communications technological tools, thus contributing to the advancement and keeping up with the great countries. This paper presents the problem of cadastral maps. The hitherto existing cadastre, consisting of paper maps and land registers, is now becoming insufficient. Its shortcomings force developments leading to its improvement. One of the ways is the creation of a Land Information System. A digital cadastral map is the main component of this system. The structure and information content of the map is presented, its differences from analogue maps are shown, and the process of map creation is described. A digital cadastral map can be the basis for additional thematic layers, successively converting it into a complex system for management of administrative units.
\end{abstract}

Keywords: Cadastral Map; Geographic Information System (GIS); Land Information System (LIS); Mapping; Surveying

\section{Introduction}

A cadastre is normally a parcel based, and up-to-date land information system containing a record of interests in land (e.g. rights, restrictions and responsibilities). It usually includes a geometric description of land parcels linked to other records describing the nature of the interests, the ownership or control of those interests, and often the value of the parcel and its improvements.

Graphical indices of these parcels, known as cadastral maps, show the relative location of all parcels in a given region. Cadastral maps commonly range from scales of 1:500 to 1:10,000. Large scale diagrams or maps showing more precise parcel dimensions and features (e.g. buildings, irrigation units, etc.) are often prepared by cadastral surveys for each parcel based on ground surveys and aerial photography. Information in the textual or attribute files of the cadastre, such as land value, ownership, or use, can be accessed by these unique parcel codes shown on the cadastral map, thus creating a complete cadastre [1].

The principal responsibility of the assessor is to locate, inventory, and appraise all property within the jurisdiction. A complete set of maps is necessary to perform this function. Maps help determine the location of property, indicate the size and shape of each parcel, and reveal geographic relationships that affect property value. Maps and map data are important not only for assessors, but also for other governmental agencies, the public, and the land information community (such as realtors, title companies, and surveyors). In addition, the assessor must track current ownership of all parcels, so that the proper party can receive assessment notices and tax bills. Computerization of map and parcel data can enhance the capability to manage, analyze, summarize, display, and disseminate geographically referenced information [2]. Working with digital cadastral maps and tabular parcel related data in a GIS, users can selectively retrieve and manipulate layers of parcel and spatial information to produce composite maps with only the data they need. Sharing GIS files over an internal or external data network makes parcel maps and related attribute information widely available, and reduces the duplication of effort inherent in separate map 
systems. Such sharing is becoming increasingly sophisticated, ranging from allowing users to download data or prepared maps, allowing users to make sophisticated queries that may draw on the power of the host GIS's software and hardware [3]. Computerized mapping systems may be referred to by several names. They include [4]:

- Geographic information system (GIS).

- Land information system (LIS).

- Digital multipurpose cadastre.

- Multipurpose land information system (MPLIS).

- Land parcel database.

\section{The Views of a GIS}

A GIS is most often associated with a map. A map, however, is only one way that can work with geographic data in a GIS, and only one type of product generated by a GIS. A GIS can provide a great deal more problemsolving capabilities than using a simple mapping program or adding data to an online mapping tool (creating a “mash-up”). A GIS can be viewed in three ways [5]:

1) The Database View.

2) The Map View.

3) The Model View.

Together, these three views are critical parts of an intelligent GIS and are used at varying levels in all GIS applications. Data needed for GIS can be obtained in various ways and are stored in a digital form, they are known as digital data in GIS today. Digital data are obtained primarily by the following means (Ibraheem, 2008):

1) Incorporating remotely sensed data into GIS.

2) Digitizing existing maps and plans.

3) Digitizing Ariel photographs (mono or stereo).

\section{Components of a Digital Cadastral Mapping System}

A digital cadastral mapping system should have the following components [3]:

- Reference to a geodetic control network.

- Current base map layer (ideally, photogrammetrically derived).

- A cadastral layer delineating all real property parcels.

- Vertical aerial photographs and/or images (ideally, ortho-rectified).

- A unique parcel identifier assigned to each parcel.

- A means to tie spatial data to attribute data (ownership and parcel characteristic files).

- Additional layers of interest to the assessor, such as municipal boundaries, zoning, soil types, and flood plains.

\section{Computerisation of Cadastral Maps}

The justification for computerizing cadastral maps in- cludes the following:

- The reduction of duplication in maintaining a cadastral base for many users.

- As a result of converting maps from one scale to another.

- To bring the cadastral map onto the same coordinate and mapping system as large scale topographic maps, thereby facilitating LIS/GIS applications.

An important issue in establishing a digital cadastral data bases (DCDB) is that computerization of the cadastral maps in general cannot be justified for land registration or land market reasons. Therefore computerization of the map requires the support of other users both financially and institutionally, [6].

At the institutional level, there is an issue of who is responsible for maintaining the DCDB and distributing the updates. Obviously it is necessary for one organization to administer the DCDB although there are various models using both government and the private sector to maintain the system [6].

\section{Large-Scale Land Information Systems}

Large-scale geographic and land information systems (GIS and LIS) are developing rapidly in local and state governments and other organizations across the country. These systems handle critical information related to land parcels, transportation, utilities, and other infrastructure and facilities. They are changing the way organizations operate and make decisions, and therefore, they affect the daily activities and lives of the citizens and customers of these organizations.

The attributes of different types of geospatial datasuch as land ownership, roads and bridges, buildings, lakes and rivers, counties, or congressional districts-can each constitute a layer or theme in GIS. (See Figure 1 for a schematic representation of data layers in GIS.)

\section{Case Study}

The development of the LIS of the study area goes through several distinct stages. The first is data collection and conversion, the second is editing and final is database development as well as brows and query functions through a user interface. Emphasis is placed on the method of organization determined to maximize brows and query efficiency and friendliness, by dialogue buttons, menus scripts under ArcGIS (9). This research was intended to introduce a design system to manage survey datasets through the production of GIS-ready information using appropriate standard and computing application. The trial implementation does instigate sufficient results at present stage whereby the test datasets consisting of raster image and feature classes were being managed carefully through the platform of producing and delivering GIS-ready in- 


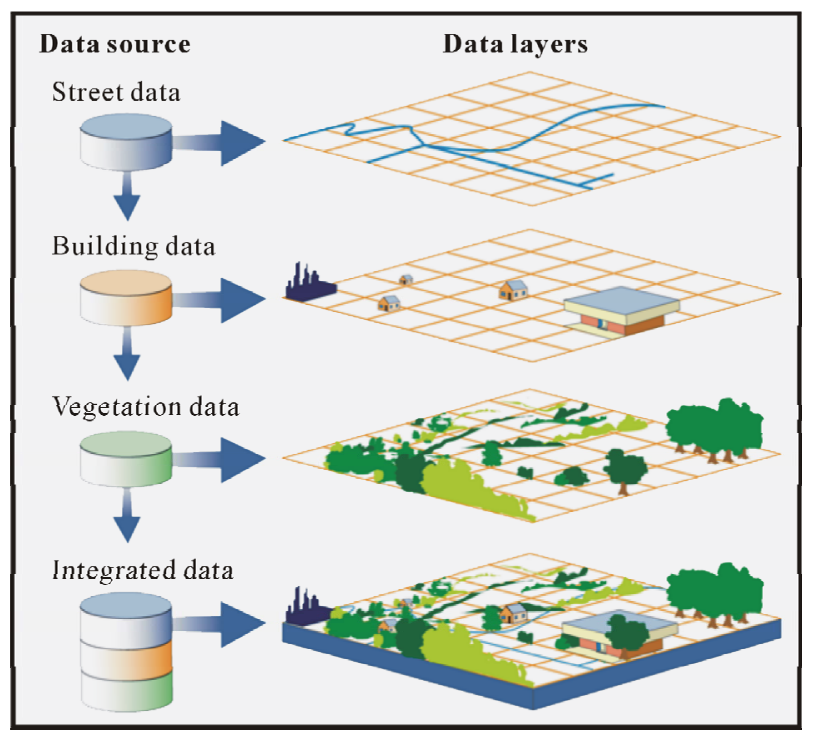

Figure 1. Example of GIS data layers or themes [7].

formation. However there is still a need for an improved flow line of the process as more dataset type and volume covering other survey datasets held in a survey organization would be used. The testing of the design and flow line has clearly shown the possibility to disseminate, retrieve and combine those data for visualization and query over the web from multiple different data sources. ArcGIS functionality is proved offering capabilities for geospatial data interchange, manipulation and management as well. The ArcGIS application has clearly shown the successes of the concept of data integration on-the-fly from multiple heterogeneous geospatial data servers.

\subsection{Data Collection and Conversion}

Both analogue and digital data are gathered for the study area including:
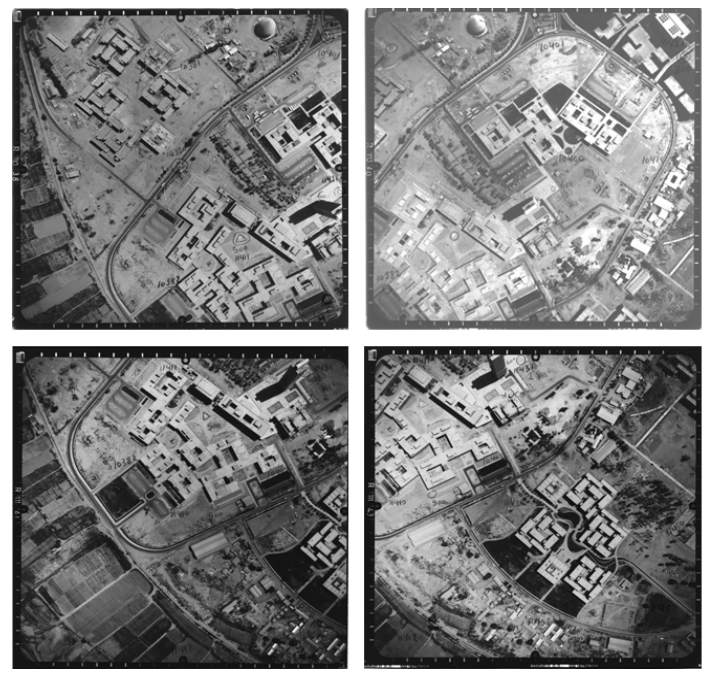

1) A digital base map for Baghdad University site.

2) Eight digital Arial photos provided by surveying department as shown in Figure 2.

3) Historical data, photographs, reproduction and surveying details.

4) Additional descriptive information was also collected.

A mosaic is an assembly of series of overlapping aerial photographs to form one continuous picture of the terrain. It may consist of a single strip of photographs, termed a strip mosaic, or it may be contain many overlapping strips. The images used in this study captured from space by the military in (July 1985) with focal length (152.16 $\mathrm{mm})$, flying height $(456.48 \mathrm{~m})$ and scale the image (1/ 3000) which is illustrated in Figure 2. The completion of this work needing to several enough aerial photos of the area. The mosaics have been found that the University of Baghdad covered pace aviation are flight (110, 111). All the airline has four images so that there is a common area shows each image of the photo that followed in the line of flight, one is called the forward overlap or overlap the front and the amount (60\%). And also there is an overlap (side lap) or (End Lap) hereunder (30\%) were converted this image to a digital format (Digital form) using (Scanner). Tthen saved on CD in the Department of Surveying Engineering, which is used to transfer this image to a calculator to work with them.

Matching the mosaic images usually implies that the radiometric intensity data from one image representing a particular feature must be matched to the intensity data from the second image, representing the same feature. This implies more than just matching image intensity data correlation, because the same piece feature may look considerably different radio metrically from different point of view, or at different time. Figure 3 shows the matching the mosaic of eight digital Arial photos of
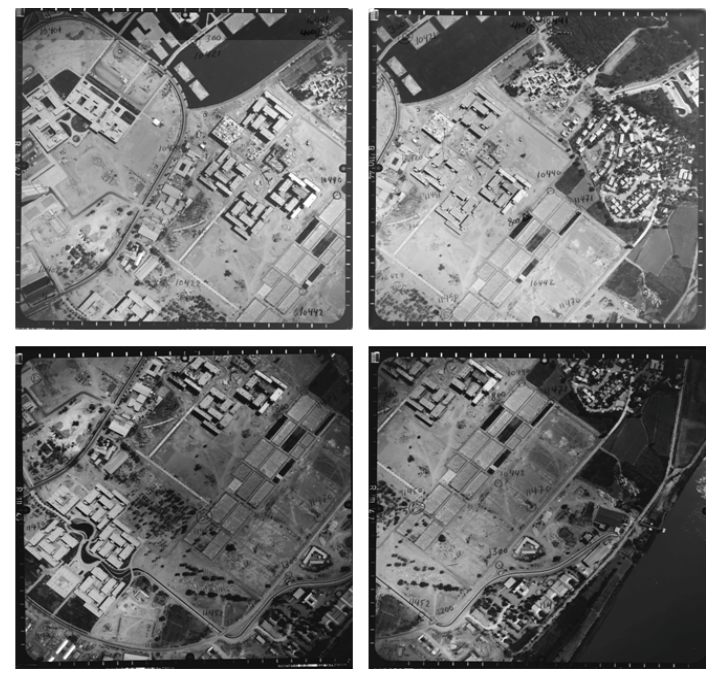

Figure 2. Eight digital Arial photos of Baghdad University site. 


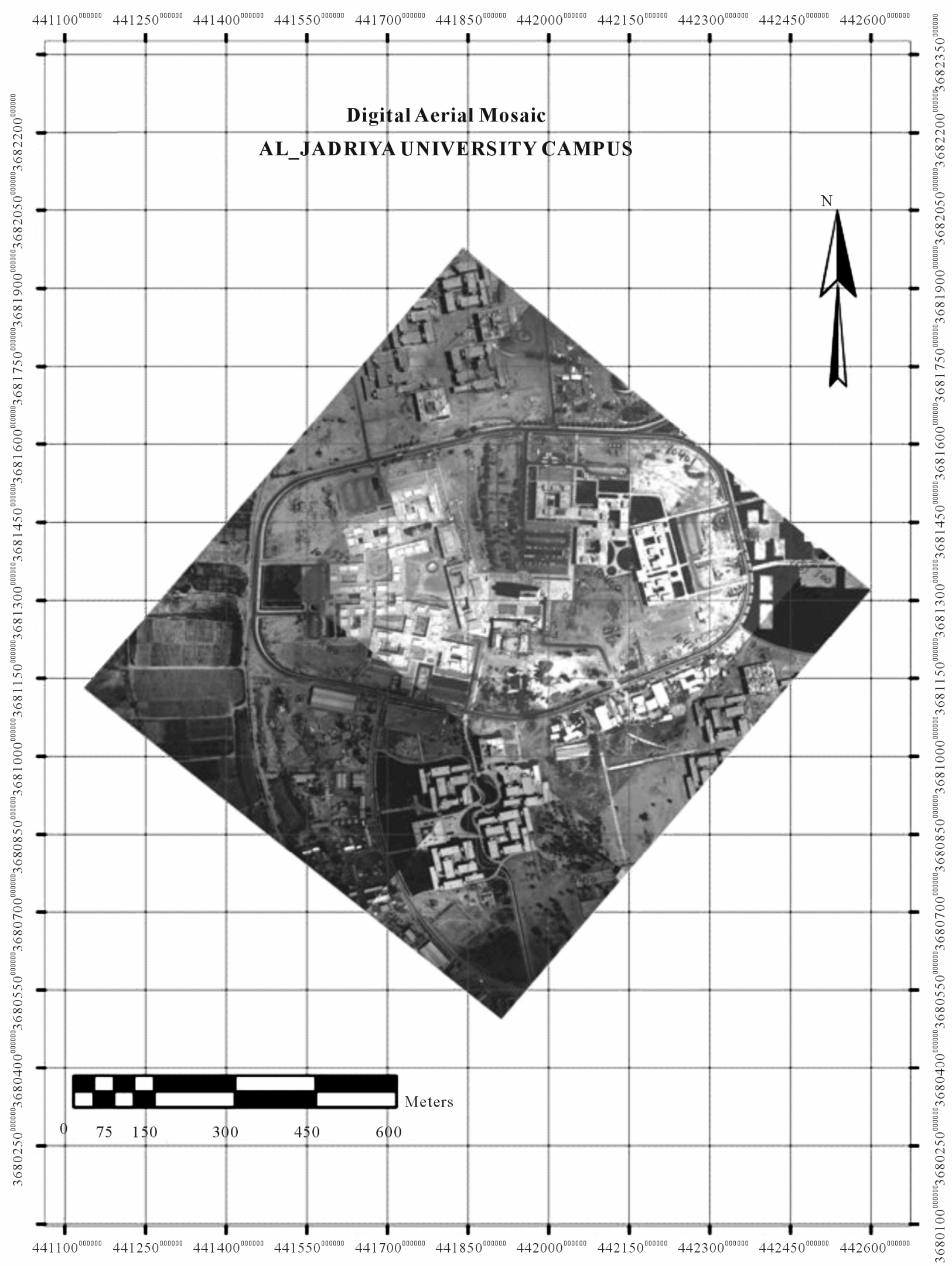

Figure 3. Matching the mosaic of eight digital Arial photos of Baghdad University site by using ERDAS LPS software. 
Baghdad University site by using ERDAS LPS (V 9.2) software.

\subsection{Lis Structure and Analysis}

The LIS's structure is performed into the ArcGIS environment, which provides easy and efficient data management and analysis. The specific application includes the integration of the above mentioned coverage into ArcGIS as themes and the implementation of the database, and organized according to the following thematic data types (Figure 4):
1) Colleges;
2) Departments;
3) Roadways;
4) Parks;
5) Green spots;
6) Channels;
7) Mosque;
8) Sport Fields;
9) Residents.

Zooming in the map, a more detailed display of the area is obtained, facilitating the investigation process. Through the use of the menu, the desired entity type is displayed, further divided into sub-types, according to specific characteristics. The Start-up screen of the system displays a map of the whole area included in the ArcGIS software (Figure 5). An error of less than 1.0000 pixels is acceptable. An error of greater than 1.0000 indicates that the points were inaccurately measured or poorly identified. But in this study the resulted accuracy Root Mean Square Error (RMSE) was (0.0775) which was very acceptable.

The ArcGIS software was used to provide a digital map with multi layers for that study area. The layers which were formed were eight layers are: layer of colleges, layer of departments, layer of roads way, layer of mosque, layer of parking, layer of sport fields, layer of gardens, layer of open channel, layer of sub roads and layer of status. Figures (6)-(8) illustrate the drawings of

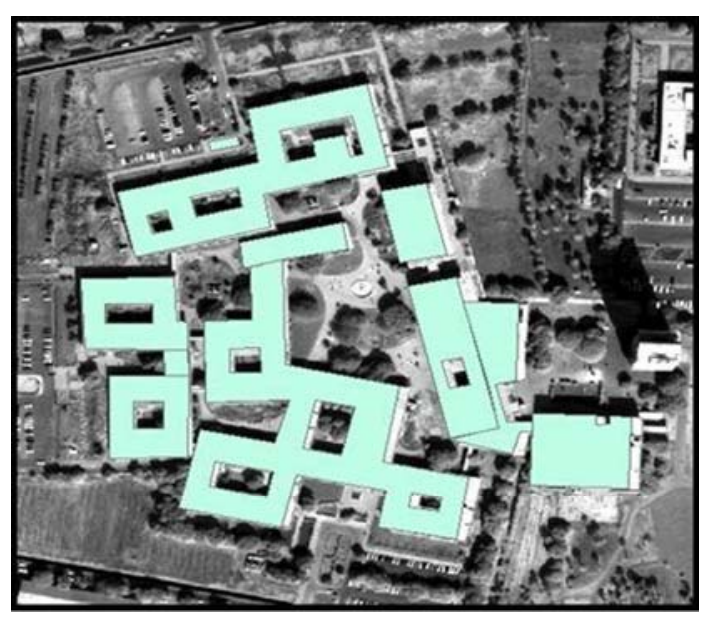

Figure 4. The zoom in the entity of College of Engineering in Baghdad University site by using ArcGIS environment.

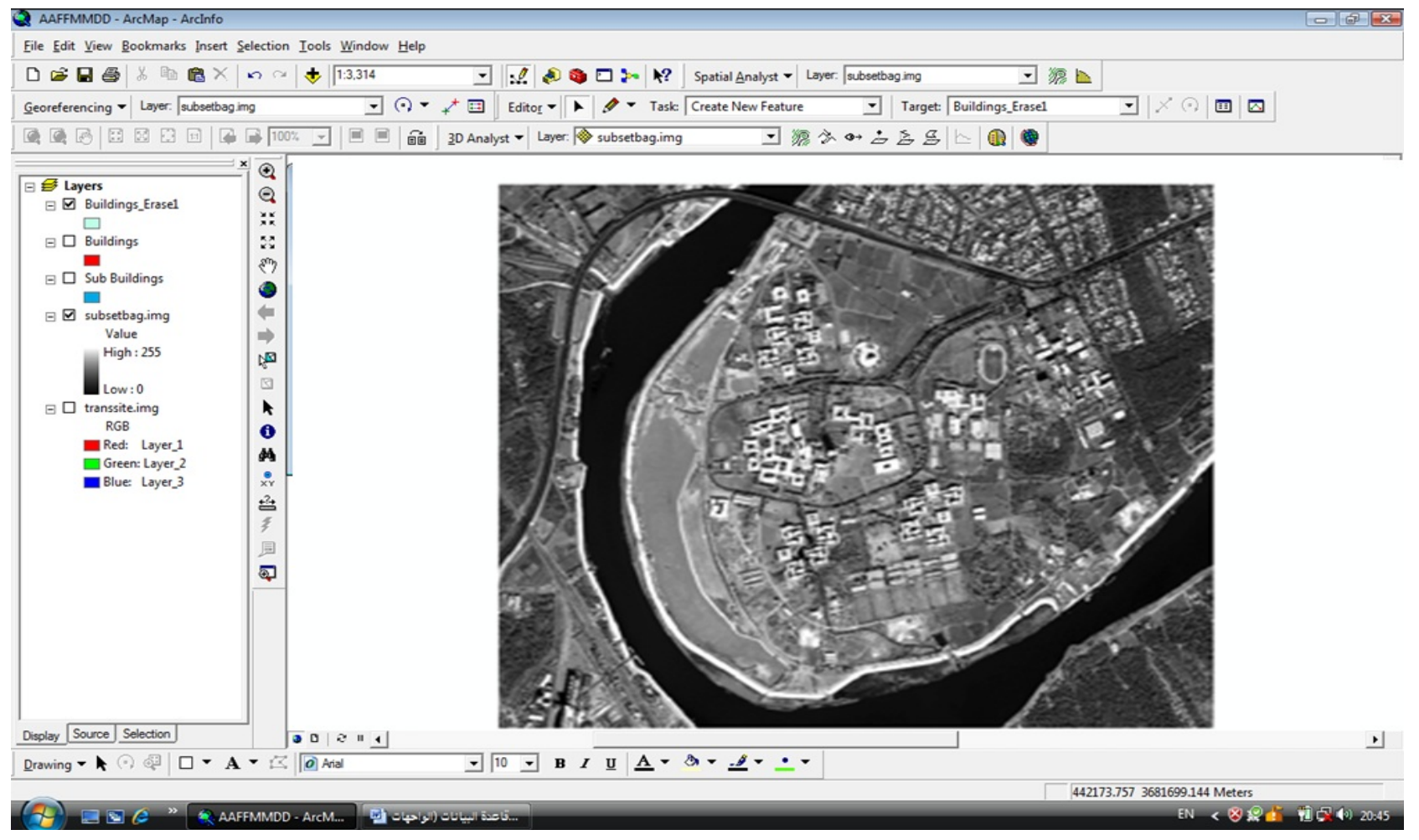

Figure 5. A thematic map of the whole area included in the ArcGIS software of College of Engineering in Baghdad University site. 
final layout - ArcMap - Arcinfo

Eile É Eit View Bookmarks Insert Selection Iools Window Help

口乞日皇

Georeferencing - Layer. transsiteimg

圆圆
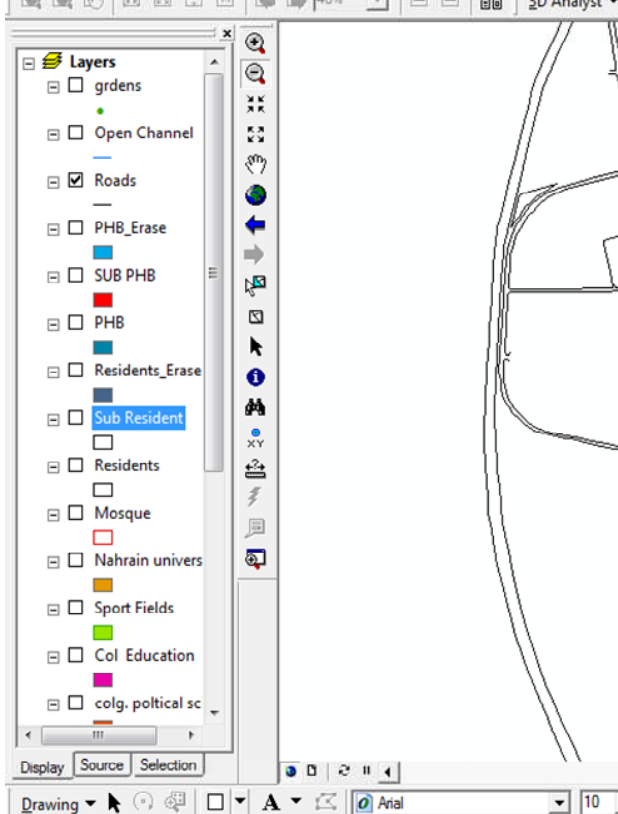

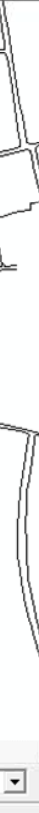

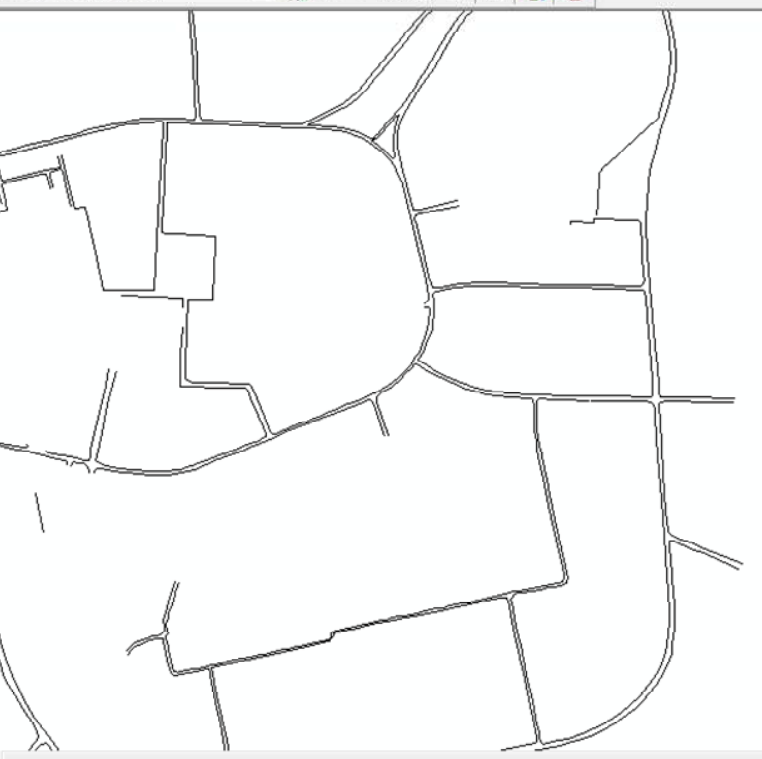

Drawing - A (?) $\square \vee \mathbf{A} \vee \square \square$ Arial

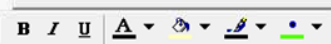

Figure 6. Layer of road way.

final layout - ArcMap - Arclnfo

File É dit View Bookmarks Insert Selection Iools Window Help

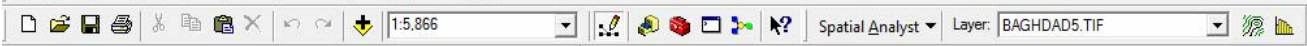

Georeferencing - Layer: transiteimg

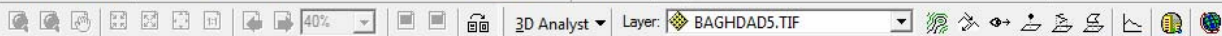

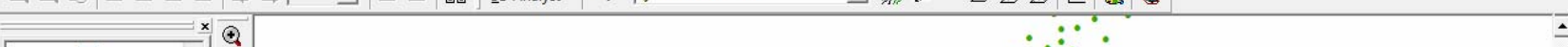

$\square \square$ Sub Resident
$\square \square$ Residents
$\square \square$ Mosque
$\square \square$ Nahrain univers
$\square \square$ Sport Fields
$\square \square$ Col Education
$\square \square$ colg. poltical sc
$\square \square$ Sub col. Engine,
$\square$
$\square \square$ College Enginet $\equiv$
$\square \square$ Sub Science
$\square \square$ Col. Science
$\square \square$ transsite.img
$\square \square$ BAGHDAD5.TIF
Value
High: 255
$\square$.

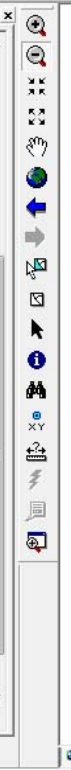

Display Source Selection 0 : 211

Drawing - A क $\square \cdot \mathbf{A}=\square$

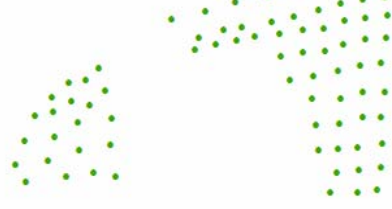

$\because \because:$

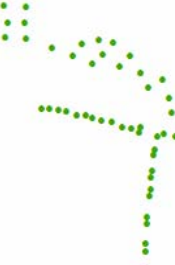

Avial

$\pm \longdiv { 1 0 . }$

B I U $\underline{\text { A }}=\underline{\underline{H}} \cdot$

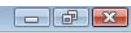

Q

Figure 7. Layer of gardens. 


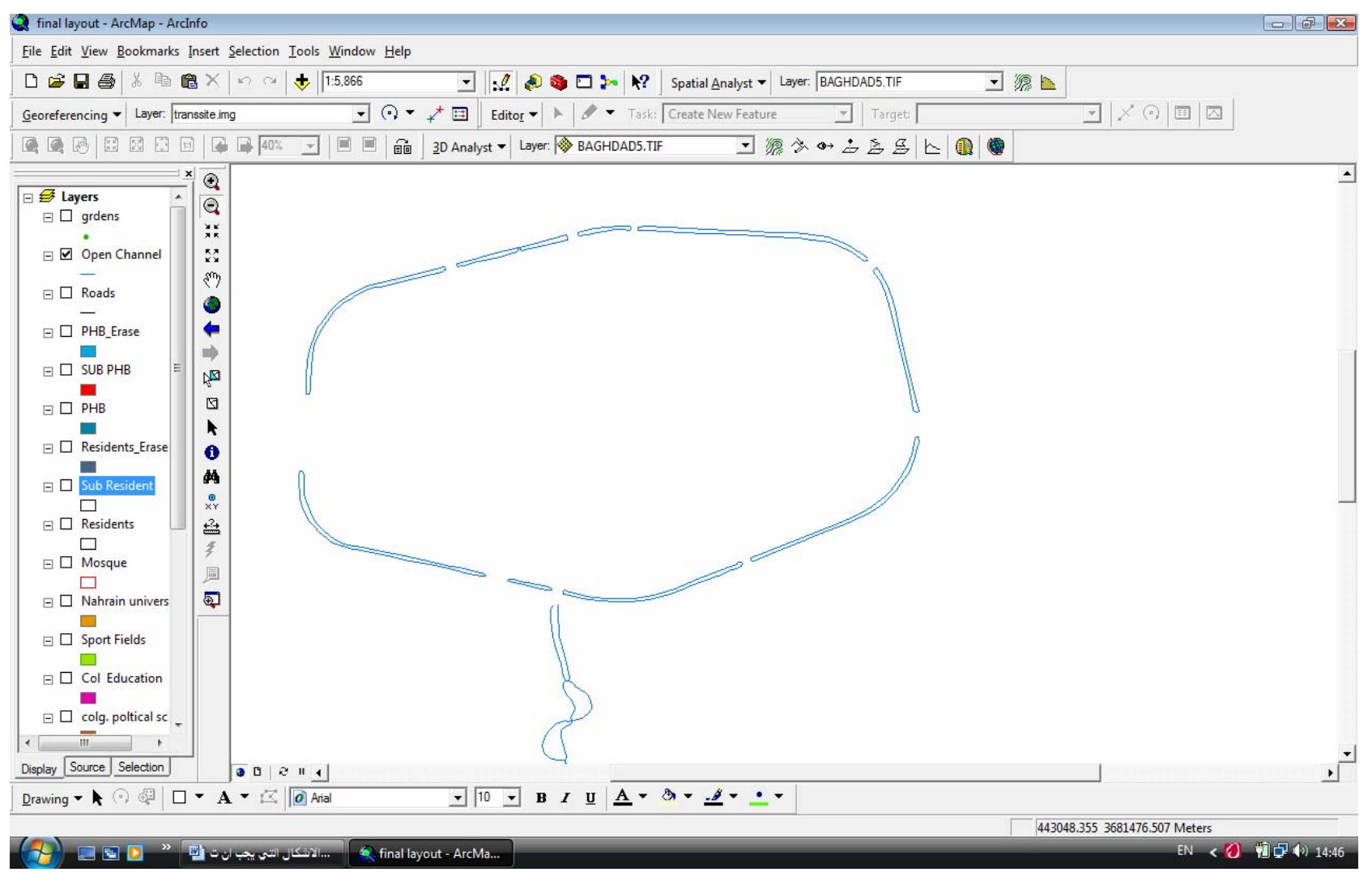

Figure 8. Layer of open channels.

some of these layers (roads way, gardens and open channel).

Clicking on the area of the interest a second dialog window is presented to the user including all the entity types of the area (Figures 9(a)-(f)). A button linked to an Arial photo of the area is also available.

The application results in digital dynamic map of $1 /$ 10,000 scale, as shown in Figure 10, associated to descriptive and multimedia information about the site of Baghdad University.

\subsection{Accuracy of Digital Mapping}

In this study, after the production of mosaic for that study area stereo pair of the final form the ArcGIS software was used to prepare a digital map with multi layers. The layers include roads layer, colleges layer, residential sectors layer, sport fields layer, parking layer, sub roads layer, gardens layer and urban places layer. After the completion of the drawing layers, the digital map was produced in its final form with scale of 1:10,000. This scale is appropriated to the scale of digital aerial photographs that were used in the production, which in turn was to be used to produce the digital map; thirteen points were selected as check points as shown in Table 1 to compute the resulted accuracy Root Mean Square Error (RMSE) by using the following equations:
Table 1. Ground control points (GCPs) in UTM system.

\begin{tabular}{cccc}
\hline Remark & Y (Easting) & $\boldsymbol{X}$ (Northing) & Sta. \\
\hline 4U.B. & 3681323.884 & 441959.883 & \\
1 & 81531.108 & 41509.005 & \\
2 & 81553.005 & 41676.445 & \\
3 & 81591.506 & 41966.536 & \\
8 & 81505.107 & 42321.602 & UTM Coordinate of \\
9 & 81233.677 & 42354.858 & Station 4U.B. \\
the National Grid. \\
10 & 81117.789 & 42067.319 & \\
11 & 81071.343 & 41858.940 & \\
12 & 81109.611 & 41702.700 & 4U.B. (4) University \\
P1 & 81184.942 & 42547.451 & \\
19 & 80536.217 & 42093.680 & \\
20 & 80542.393 & 41904.364 & \\
21 & 80706.598 & 41734.572 & \\
\hline
\end{tabular}

$$
R_{i}=\sqrt{R x_{i}^{2}+R y_{i}^{2}}
$$

where

$R_{i}$ : The RMSE for check point (i).

$R x_{i}$ : The $X$ residual for check point (i), (the distance between the source and the transformed coordinates in $x$ 


\section{AAFFMMDD - ArcMap - Arclnfo}

Eile Edit View Bookmarks Insert Selection Iools Window Help
口回是
他的 $\times \mid n$
$\pm 1: 3,314$
- :! $\square$ 20 4 ? Spatial Analyst - Layer: subsetbagimg
- 㣪以
Georeferencing - Layer: subsetbagimg

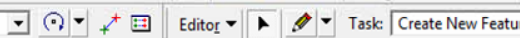
Target Buildings_Erase 二

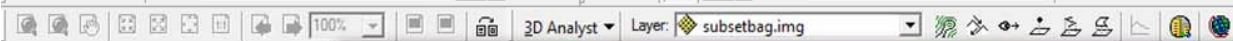

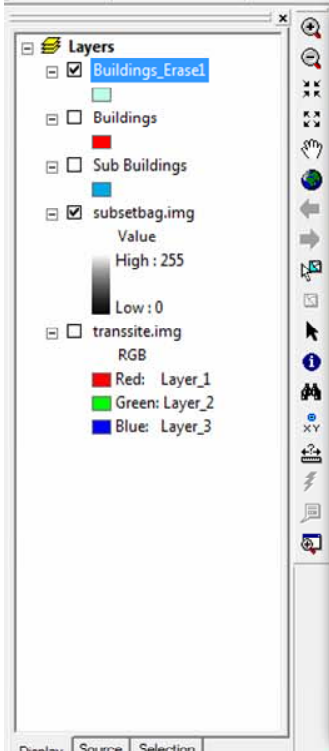

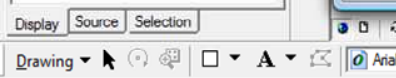

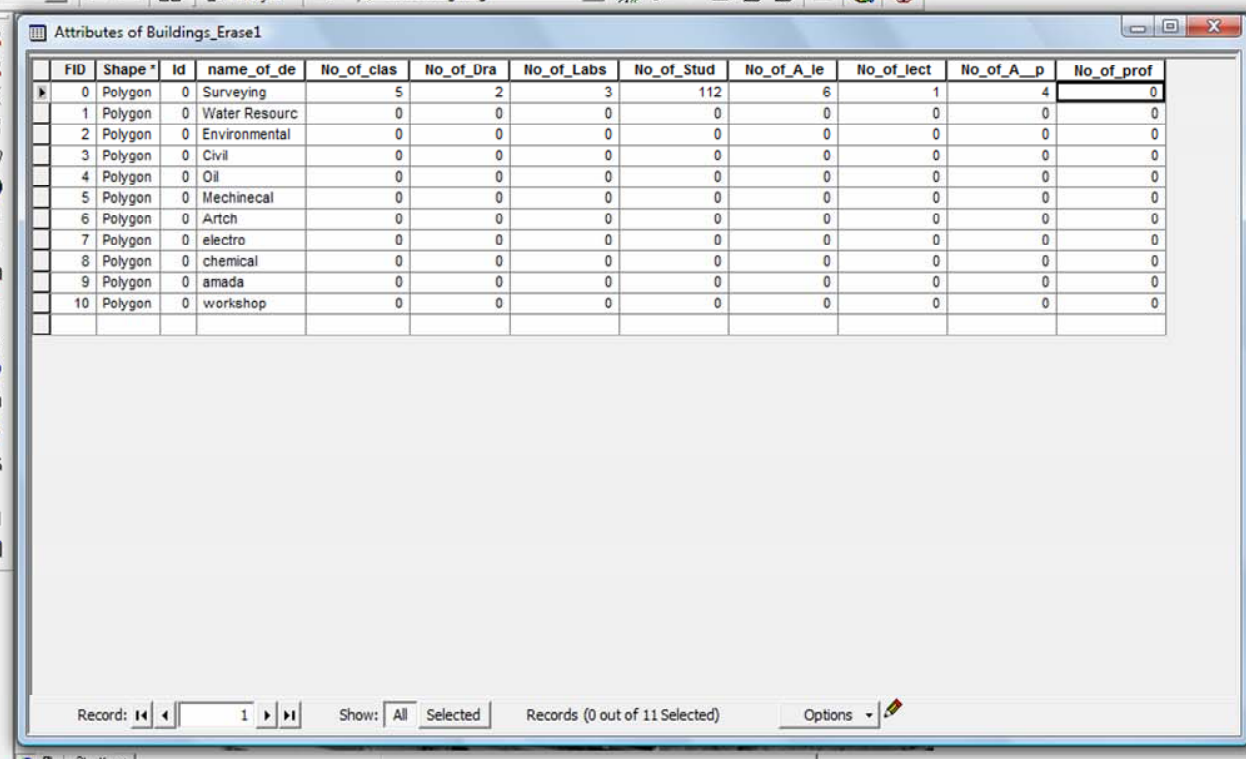

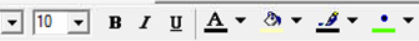

441943.1273682059 .558 Meters

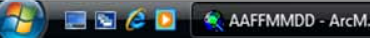

(a)

AAFFMMDD - ArcMap - Arclnfo

File É dit View Bookmarks Insert Selection Iools Window Help

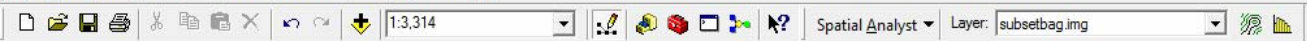

Georeferencing - Layer: Ssubsetbag.img

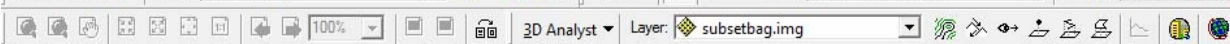

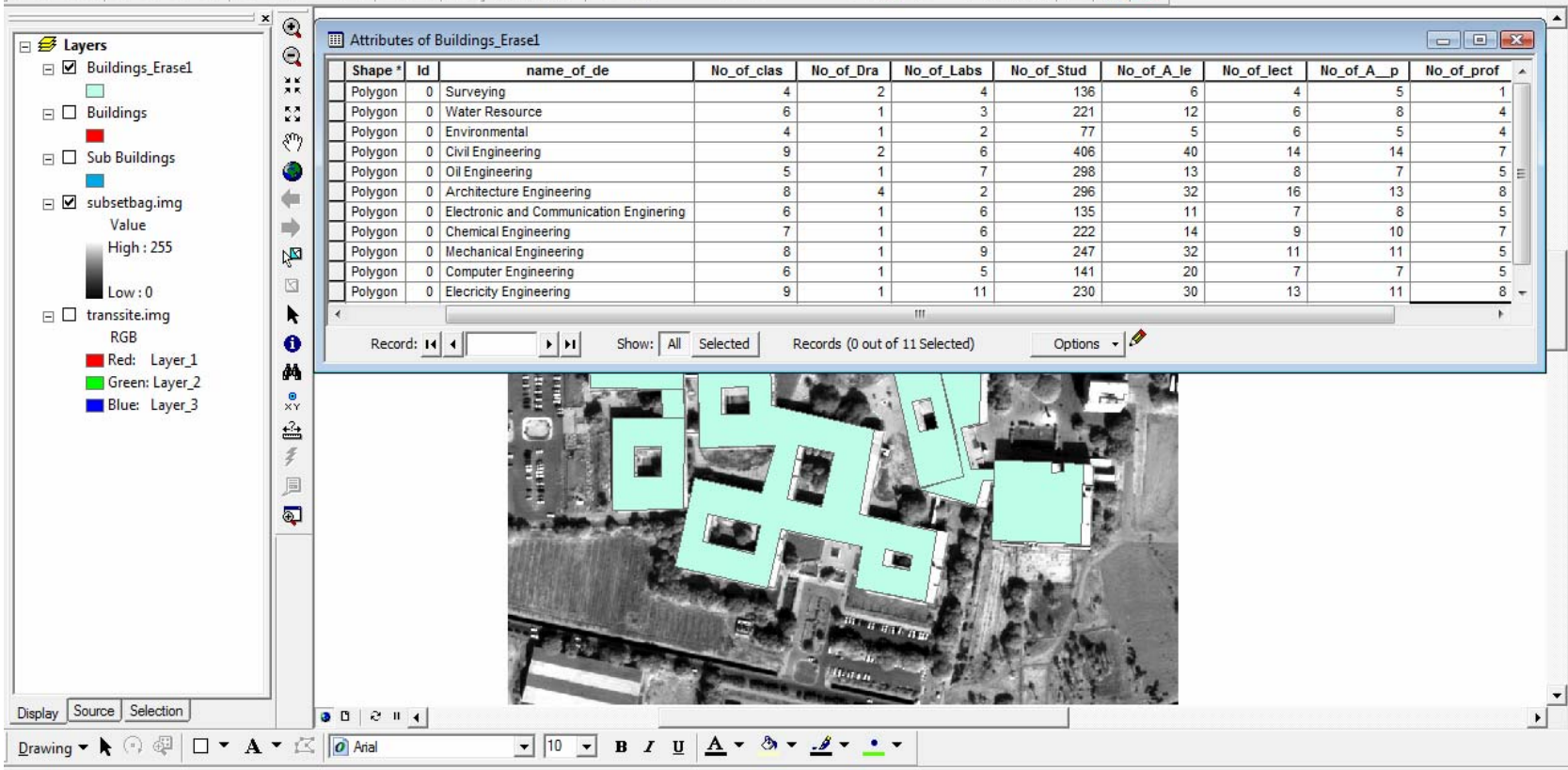

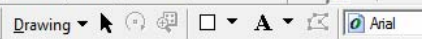




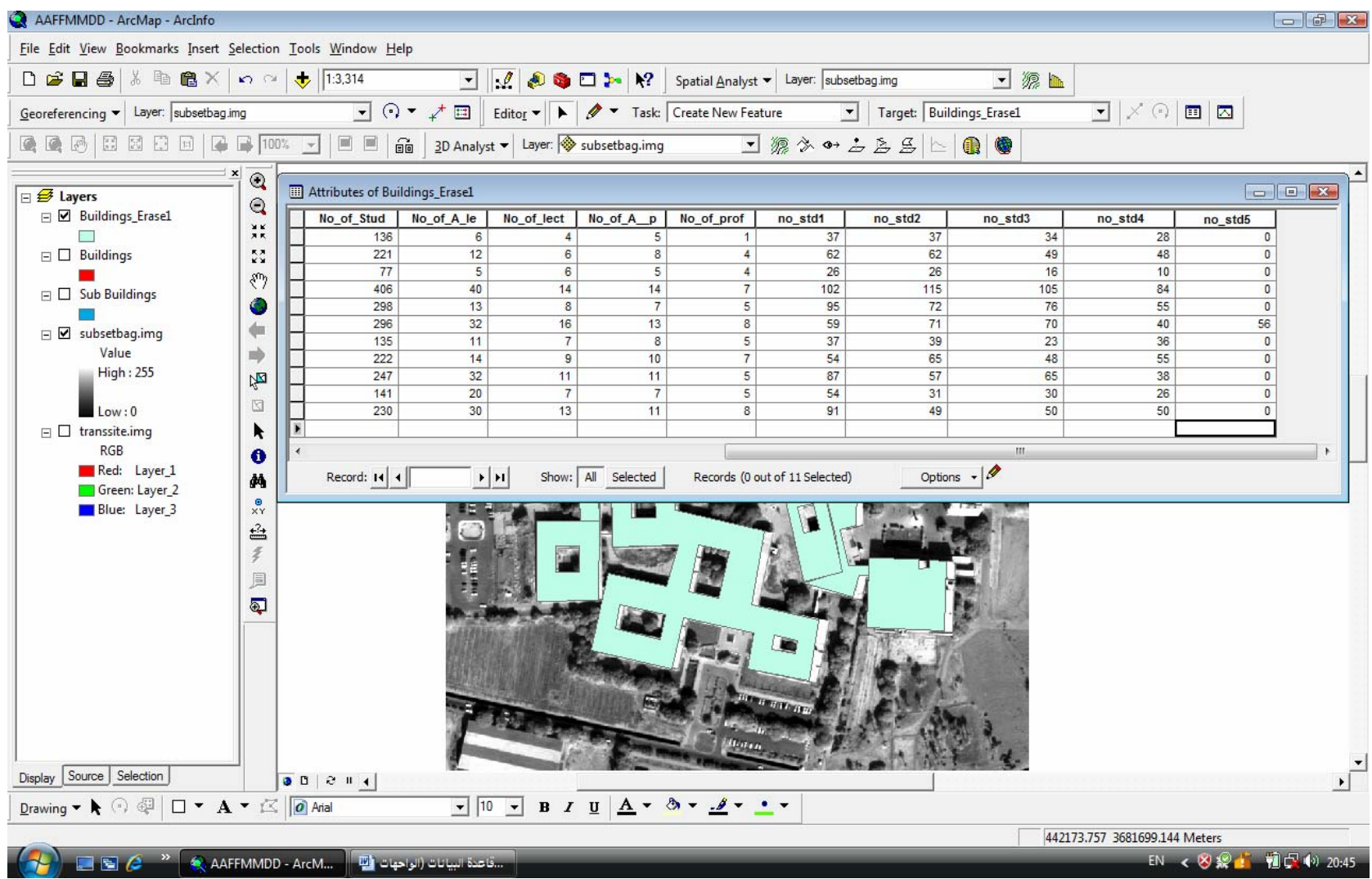

(c)

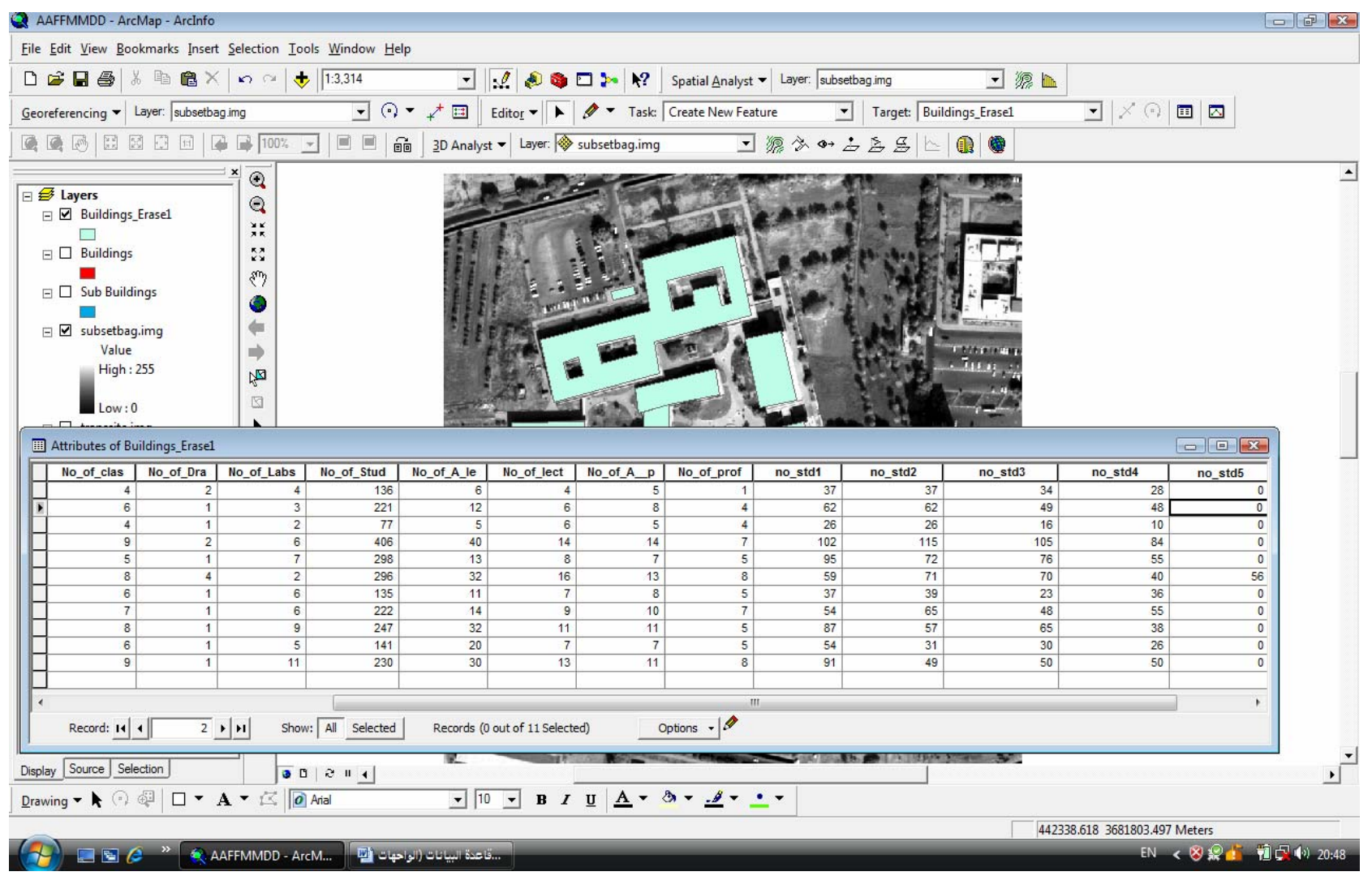




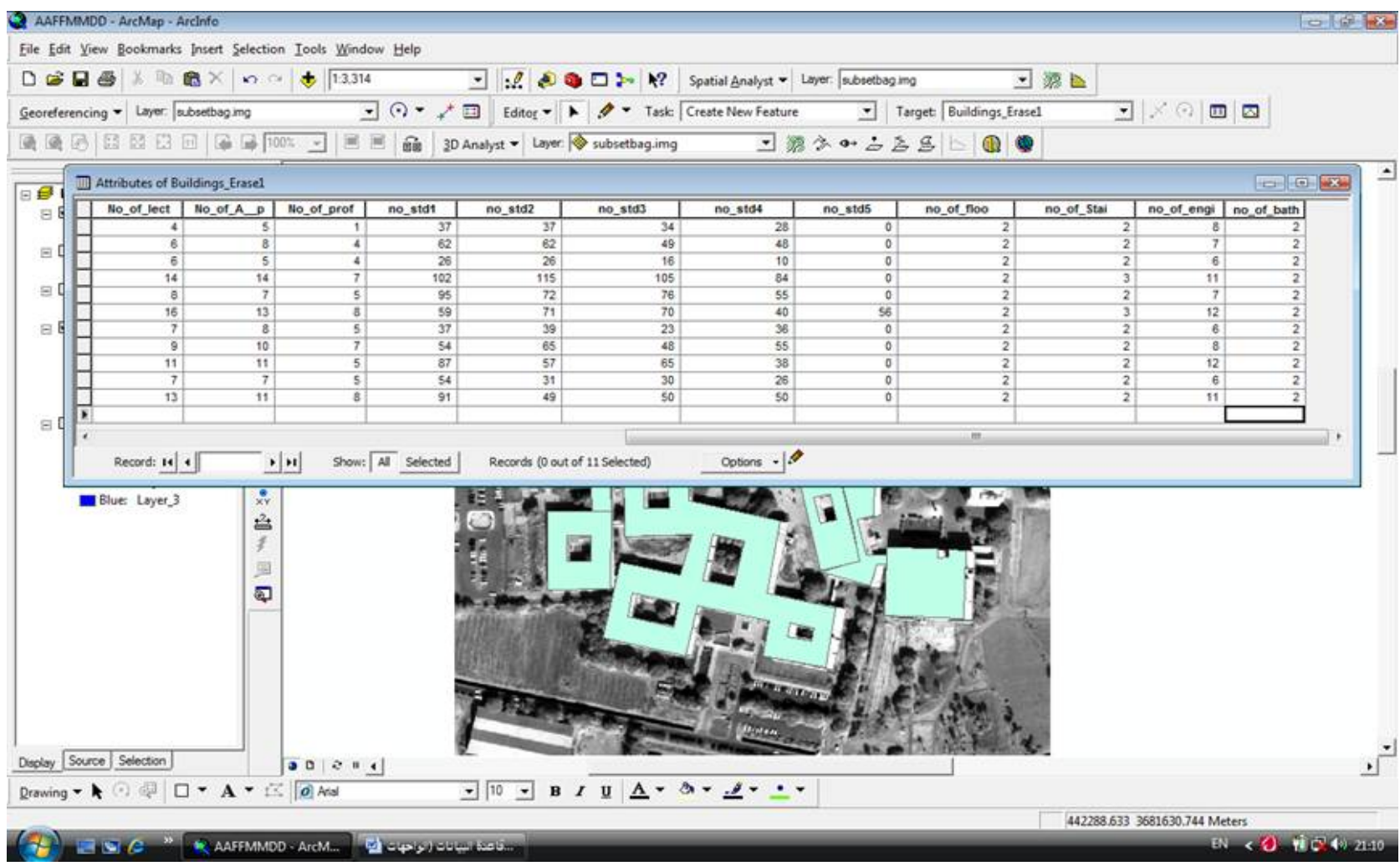

(e)

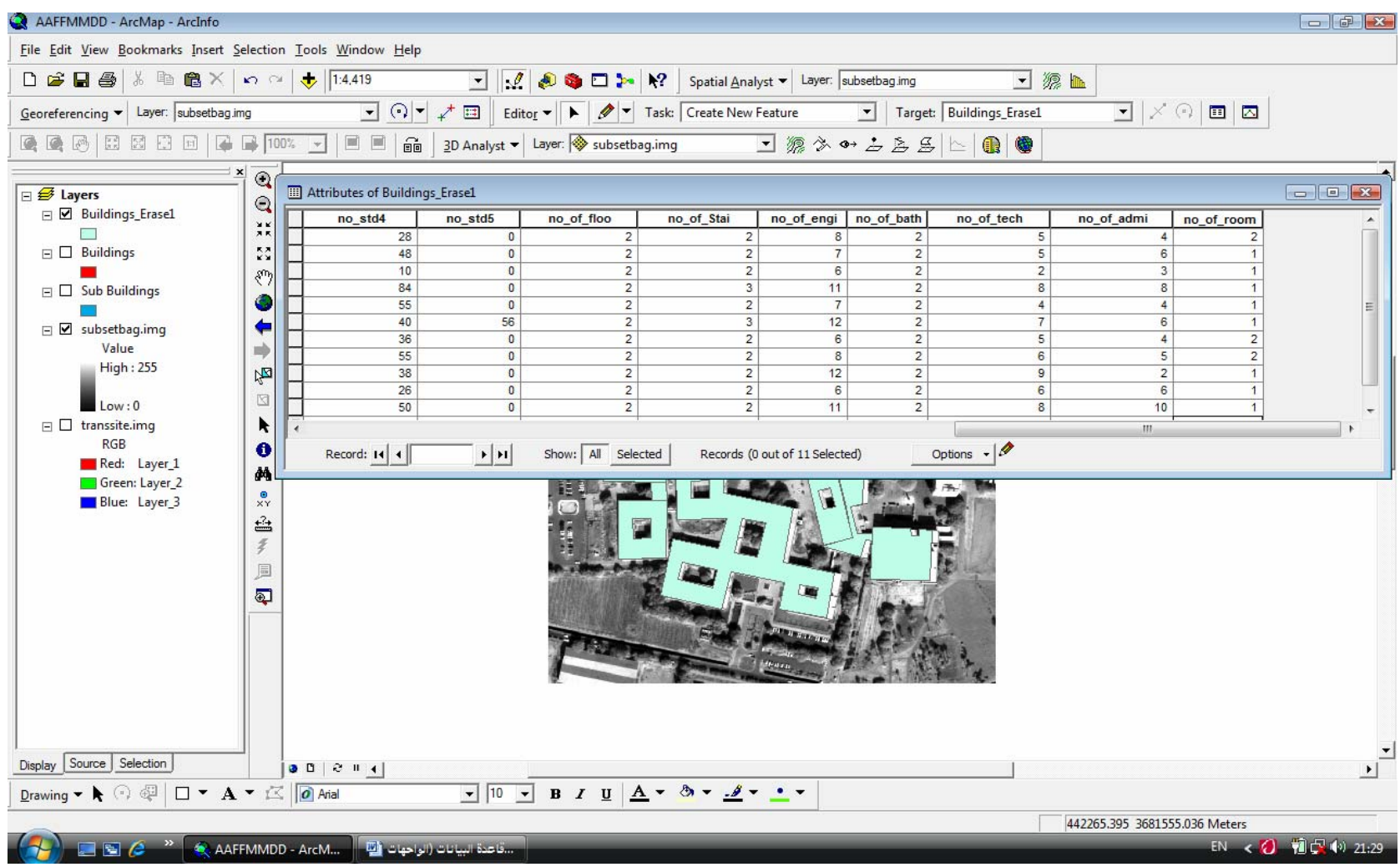

(f)

Figure 9. Dialog windows of the database included in the ArcGIS software of College of Engineering in Baghdad University site. 


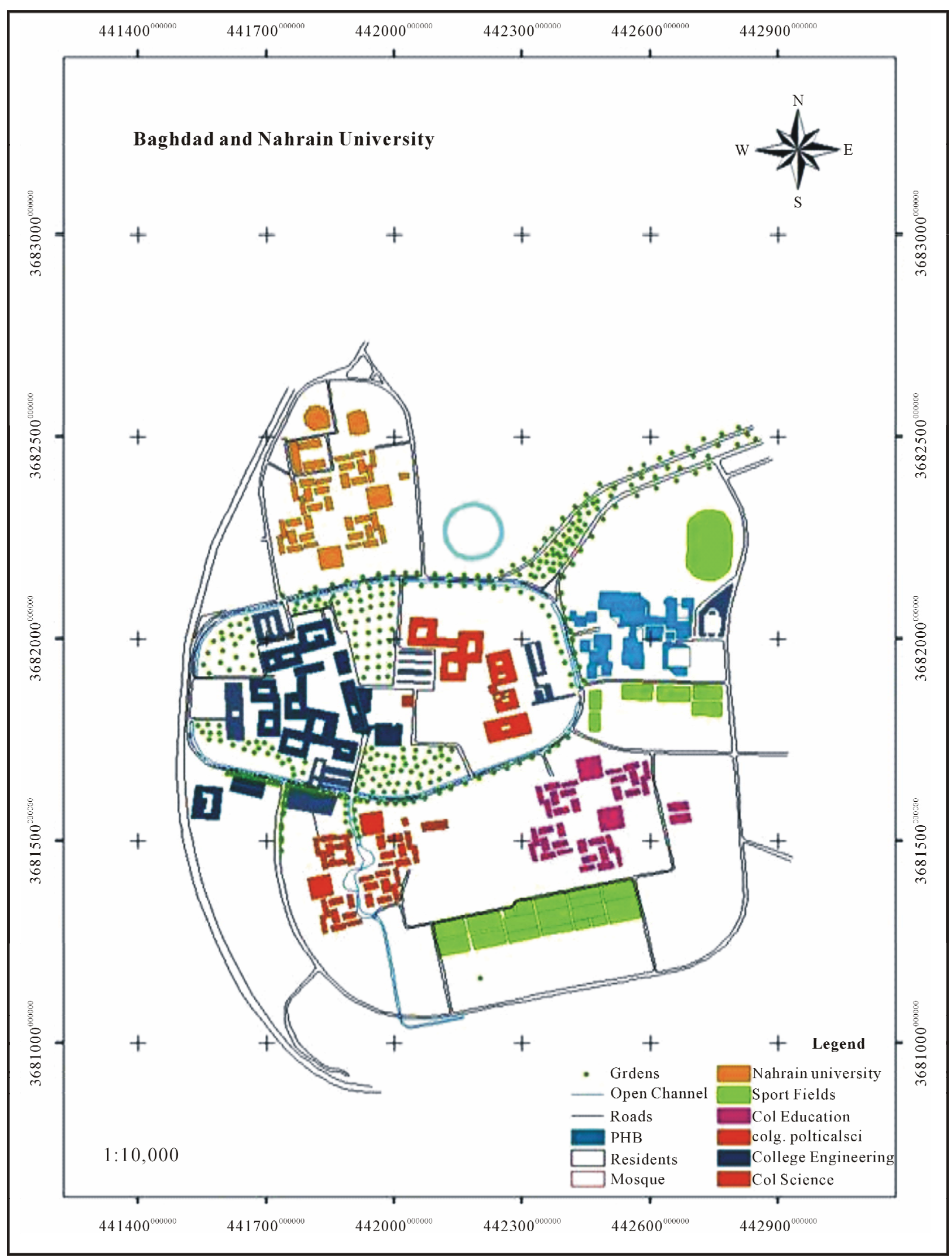

Figure 10. The digital cadastral map of Baghdad University site by using ArcGIS environment, scale 1:10,000. 
direction).

$R y_{i}$ : The $Y$ residual for check point (i), (the distance between the source and the transformed coordinates in $\mathrm{y}$ direction).

Depending upon the residuals, the RMSE in $X$ coordinate, the RMSE in $Y$ coordinate, and the total RMSE can be computed from the following equations:

$$
\begin{aligned}
& R_{x}=\sqrt{\frac{1}{n} \sum_{i=1}^{n} R_{x i}^{2}} \\
& R_{y}=\sqrt{\frac{1}{n} \sum_{i=1}^{n} R_{y i}^{2}} \\
& R_{T}=\sqrt{R_{x}^{2}+R_{y}^{2}}
\end{aligned}
$$

where:

$R_{T}$ : total Root Mean Square Error (RMSE).

$n$ : number of check points.

Thirteen point were selected for the checking the accuracy in digital map, the resulted accuracy ((Root Mean Square Error (RMSE)) computed by using a special Equation (4) as described above was $55 \mathrm{~cm}$, which was suitable for the production of large scale mapping. The selected scale map is suitable and appropriate for the scale of aerial photographs that have been used in the production of the map, and the possible use of the map produced and used at any time possible and updates its data using Geographic Information System (GIS) software.

\section{Conclusions}

It is well known that GIS has already become a standard tool for handling spatial data. GIS are now more commonplace in Iraq. Adding multimedia material and organizing friendly entries and alternative search techniques, the system then becomes an efficient tool for different users. Until only a few years ago the map was perceived as a static, plain view of preselected areas, available at fixed scales and, due to the development of the landscape, often out of date. Now, it is evolving into a dynamic, continually updated network of interrelated databases with volumes of geographically referenced information linked to a comprehensive digital cadastral database. As shown above, our study results in efficient Land Information System for the study area. This system may be improved, by adding the following steps:

1) Promote and ensure the reliability and integrity of large-scale land information systems and Facilitate collaboration between GIS and surveying professionals at the local, regional, and national levels.

2) Promote the use of sound surveying and mapping principles in the development and the use of land information systems.

3) Foster the development and adoption of useful standards, specifications, and procedures for the development, operations, and the use of land information systems.

4) The LIS's structure conducts the user's navigation through alternative searching paths, created by the application.

\section{REFERENCES}

[1] J. L. G. Henssen, "Cadastre, Indispensable for Development," International Institute for Aerospace Survey and Earth Sciences (ITC), Enschede, 1990.

[2] G. Larsson, "Land Registration and Cadastral Systems," Longman Scientific and Technical, New York, 1991.

[3] W. Y. Wan and I. P. Williamson, "A Review of the Digital Cadastral Databases in Australia and New Zealand,” The Australian Surveyor, Vol. 40, No. 1, 1995, pp. 41-52.

[4] ASCE Editorial, "Basic of Geographic Information System,” Journal of Computing in Civil Engineering, ASCE, January 1998, pp. 1-4.

[5] A. Th. Ibraheem, "The Application of Geographical Information System in Civil Engineering,” Integrating Teaching and Research with Community Service, Book No. 87, University of Sharjah, Sharjah, 2008, pp. 436- 455.

[6] I. Williamson and S. Enemark, "Cadastre and Land Management,” The University of Melbourne, Melbourne, 1994.

[7] P. Folger, "Geospatial Information and Geographic Information Systems (GIS): Current Issues and Future Challenges,” CRS Report, Washington DC, 2009. 